\title{
Queuosine modification protects cognate tRNAs against ribonuclease cleavage
}

\author{
XIAOYUN WANG, ${ }^{1}$ ZANETA MATUSZEK, ${ }^{1}$ YONG HUANG,${ }^{2}$ MARC PARISIEN,${ }^{3}$ QING DAI, ${ }^{1}$ WESLEY CLARK, \\ MICHAEL H. SCHWARTZ, ${ }^{1}$ and TAO PAN ${ }^{1}$ \\ ${ }^{1}$ Department of Biochemistry and Molecular Biology, University of Chicago, Chicago, Illinois 60637, USA \\ ${ }^{2}$ Department of Medicine, Knapp Center for Biomedical Discovery, University of Chicago, Chicago, Illinois 60637, USA \\ ${ }^{3}$ Alan Edwards Centre for Research on Pain, McGill University, Montréal, QC H3A 0G4, Canada
}

\begin{abstract}
Eukaryotic transfer RNAs (tRNA) contain on average 13 modifications that perform a wide range of roles in translation and in the generation of tRNA fragments that regulate gene expression. Queuosine $(Q)$ modification occurs in the wobble anticodon position of tRNAs for amino acids His, Asn, Tyr, and Asp. In eukaryotes, $Q$ modification is fully dependent on diet or on gut microbiome in multicellular organisms. Despite decades of study, cellular roles of $Q$ modification remain to be fully elucidated. Here we show that in human cells, $Q$ modification specifically protects its cognate tRNA ${ }^{\text {His }}$ and tRNA $^{\text {Asn }}$ against cleavage by ribonucleases. We generated cell lines that contain completely depleted or fully Qmodified tRNAs. Using these resources, we found that $Q$ modification significantly reduces angiogenin cleavage of its cognate tRNAs in vitro. $Q$ modification does not change the cellular abundance of the cognate full-length tRNAs, but alters the cellular content of their fragments in vivo in the absence and presence of stress. Our results provide a new biological aspect of $Q$ modification and a mechanism of how $Q$ modification alters small RNA pools in human cells.
\end{abstract}

Keywords: queuosine modification; tRNA; tRNA fragment

\section{INTRODUCTION}

Transfer RNAs (tRNAs) are essential for protein synthesis. Among all RNA species, tRNAs undergo the greatest number of chemically diverse modifications. Eukaryotic tRNAs contain on average over 13 modifications. A great number of modifications are found at position 34, the wobble anticodon nucleotide (Phizicky and Hopper 2010; El Yacoubi et al. 2012). Growing evidence indicates that tRNA modifications are critical for many aspects of tRNA functions such as folding, stability, and decoding (Kirchner and Ignatova 2015). tRNA modifications also play important roles in human diseases (Torres et al. 2014).

Queuosine is a hypermodified 7-deaza-guanosine that occurs at the wobble anticodon position 34 of four tRNAs for amino acids His, Asn, Tyr, and Asp with 5'GUN anticodons (recently reviewed in Fergus et al. 2015). Queuosine (Q) is the nucleoside; the modified base is designated as queuine. Bacteria synthesize queuine through a multistep biosynthesis pathway that results in the wobble Q34 base in these four tRNAs. Eukaryotes do not synthesize queuine, but rely on dietary sources and/or the gut microbes to ob-

Corresponding authors: xwang13@uchicago.edu, taopan@ uchicago.edu

Article is online at http://www.rnajournal.org/cgi/doi/10.1261/rna. 067033.118. tain queuine, which is exchanged for the $\mathrm{G} 34$ base in the same four tRNAs by an enzyme encoded in the genomes. In humans, queuine produced by the gut microbiome is taken up by all cells and incorporated into the wobble anticodon nucleotide by the heterodimeric enzyme of OTRT1/OTRT2 (formerly OTRTD1, Supplemental Fig. S1). Thus, $\mathrm{Q}$ modification in human cells can depend on microbiome activity. The physiological requirements for the tRNA Q modifications in eukaryotes have been documented for decades, linking its relationship to many biological processes such as development, cancer, and tyrosine biosynthesis (Fergus et al. 2015). The role of $Q$ modification in cells was suggested to be related to codon-biased translation of discrete mRNA transcripts given that $\mathrm{Q}$ modification is located in the wobble anticodon position critical for codon recognition (Yasukawa et al. 2001; Zaborske et al. 2014; Endres et al. 2015). Using the Turnip yellow mosaic virus coat protein mRNA as a reporter in Xenopus oocyte, Q-modified tRNA ${ }^{\text {His }}$ was found to decode the His codons CAU/CAC equally, while

\footnotetext{
(C) 2018 Wang et al. This article is distributed exclusively by the RNA Society for the first 12 months after the full-issue publication date (see http://rnajournal.cshlp.org/site/misc/terms.xhtml). After 12 months, it is available under a Creative Commons License (Attribution-NonCommercial 4.0 International), as described at http://creativecommons.org/licenses/by-nc/4.0/.
} 
unmodified tRNA ${ }^{\text {His }}$ (G34) preferred CAC over CAU (Meier et al. 1985). Whether this result can be applied transcriptome-wide, however, is unknown. Q modification may also tune translational fidelity which has led to genome-wide reprogramming of coding sequences in Drosophilids (Zaborske et al. 2014).

A recent study in the fission yeast Schizosaccharomyces pombe showed that $\mathrm{Q}$ modification directly affects the activity of Dnmt2-dependent $\mathrm{m}^{5} \mathrm{C} 38$ modification in tRNA $^{\text {Asp }}$, suggesting an unanticipated role of $\mathrm{Q}$ modification in RNA metabolism (Muller et al. 2015; Ehrenhofer-Murray 2017). Dnmt2 modifies $m^{5} \mathrm{C} 38$ in three tRNA isoacceptors among which only tRNA ${ }^{\text {Asp }}$ contains $\mathrm{Q}$ modification. Previous work in Drosophila found that $m^{5} \mathrm{C} 38$ methylation by Dnmt2 protects cognate tRNAs against stress-induced cleavage and affects the biogenesis of tRNA-derived RNA fragments, which are functional small RNAs, especially in response to stress conditions (Lee et al. 2009; Yamasaki et al. 2009; Schaefer et al. 2010; Goodarzi et al. 2015).

tRNA fragments have recently received considerable attention due to their effects in the regulation of gene expression (Raina and Ibba 2014; Goodarzi et al. 2015; Kumar et al. 2016). tRNA fragments can be generated by multiple cellular ribonucleases; angiogenin among the best characterized (Yamasaki et al. 2009; Emara et al. 2010; Ivanov et al. 2011). Angiogenin is a stress-activated member of the RNase A superfamily. This human protein cleaves tRNA molecules within anticodon loops, leading to the production of tRNA-derived stress-induced fragments which are components of the cellular stress response program (Fu et al. 2009; Yamasaki et al. 2009; Ivanov et al. 2011).

Here, we investigated the role of $\mathrm{Q}$ modification in tRNA fragment generation in human cells. We generated cell lines fully depleted of $\mathrm{Q}$ modification and the same cells with fully Q-modified tRNAs. Using these resources we show that in vitro, $\mathrm{Q}$ modification protects cognate tRNAs against angiogenin cleavage in their anticodon loops. We applied high-throughput sequencing of fulllength tRNAs and of tRNA fragments and found that although $\mathrm{Q}$ modification did not alter the levels of full-length tRNA, Q-modified cognate tRNA fragments were present in substantially higher levels in cells without $\mathrm{Q}$ modification. We also show that $\mathrm{Q}$ modification protects against cognate tRNA cleavage in vivo upon oxidative stress, thus altering the cellular tRNA fragment pools. Our study suggests a previously uncharacterized link between $\mathrm{Q}$ modification and small RNA metabolism in human cells.

\section{RESULTS AND DISCUSSION}

\section{Generation of 00 and 1000 cell lines}

In order to investigate the role of tRNA $\mathrm{Q}$ modifications, cells devoid of $\mathrm{Q}$ modifications are required. As a nones- sential modification, $\mathrm{Q}$ depleted cells may be obtained either by knocking out the QTRT1 gene or by queuine depletion in the culture medium (Rakovich et al. 2011). We went with the queuine depletion approach as QTRT1 knockout may alter the physiological response of the cell. We found that HEK293T cells had considerable amounts of $\mathrm{Q}$ modifications in the cognate tRNA ${ }^{\text {His }}$ and tRNA ${ }^{\text {Asn }}$ when cultured with regular fetal bovine serum, ranging from 10\%-60\% (not shown). This result was consistent with previous reports that cells could obtain tRNA Q-modification by taking up the small molecule queuine from regular FBS used in cell culture, whereas using dialyzed FBS avoided this issue (Gunduz and Katze 1984; Zallot et al. 2014). We generated Q-depleted HEK293T cells by growing them in dialyzed FBS through continuous passages until the $\mathrm{Q}$ modification became undetectable, while $\mathrm{Q}$ modification in tRNA ${ }^{\text {His }}$ and tRNA ${ }^{\text {Asn }}$ was fully restored by adding queuine to the medium (Fig. 1A). $\mathrm{Q}$ modifications in tRNA ${ }^{\text {Asp }}$ and tRNA ${ }^{\text {Tyr }}$ were not detected by our 3-acrylamidophenylboronic acid (APB) gel-based method due to further glycosylation of these Q-modified tRNAs that eliminated the cis-diol in the $\mathrm{Q}$ base responsible for the shift of the modified tRNA in the APB gel (Kasai et al. 1976). We performed HPLC of the completely nuclease-digested, purified tRNA ${ }^{T y r}$ and tRNA ${ }^{\text {Asp }}$ followed by mass spectrometry to identify the presence of galactose-Q (galQ) in tRNA $A^{\text {Tyr }}$ and mannose-O (manQ) in tRNA ${ }^{A s p}$ in tRNAs isolated from 1000 cells (Supplemental Fig. S2). We identified galQ and manQ from both UV absorbance profile and the mass of the modified nucleotide $5^{\prime}$ monophosphate.

We measured the time course for HEK293T cells to fully restore $\mathrm{Q}$ modification in tRNA ${ }^{\text {Asn }}$ (Fig. 1B). tRNA ${ }^{\text {Asn }}$ became fully modified after $\sim 8 \mathrm{~h}$ in the presence of queuine. We designated the completely Q-depleted cells as 00 cells and fully Q-modified cells as 1000 cells hereafter. We focused on tRNA ${ }^{\text {His }}$ and tRNA ${ }^{\text {Asn }}$ in our subsequent studies since for these cognate tRNAs, $\mathrm{Q}$ modification levels and the resulting properties could be directly assessed.

\section{Q modification and tRNA cleavage by angiogenin in vitro}

The ribonuclease angiogenin primarily targets tRNA anticodon loops for cleavage in vivo (Anderson and Ivanov 2014; Ivanov et al. 2014). We reasoned that the $Q$ modification in the wobble anticodon position may directly affect angiogenin cleavage of the cognate, Q-modified tRNAs. Total tRNAs from 00 and 1000 cells were $5^{\prime 32} \mathrm{P}$-labeled and gel purified, and incubated with recombinant human angiogenin protein either at varying concentration or incubation time (Fig. 1C,D). We quantified the fraction of products for tRNA fragments of all sizes from angiogenin cleavage throughout the tRNA body and those corresponding to tRNA halfmers which were derived from cleavage in the anticodon loop, and compared the amount of 

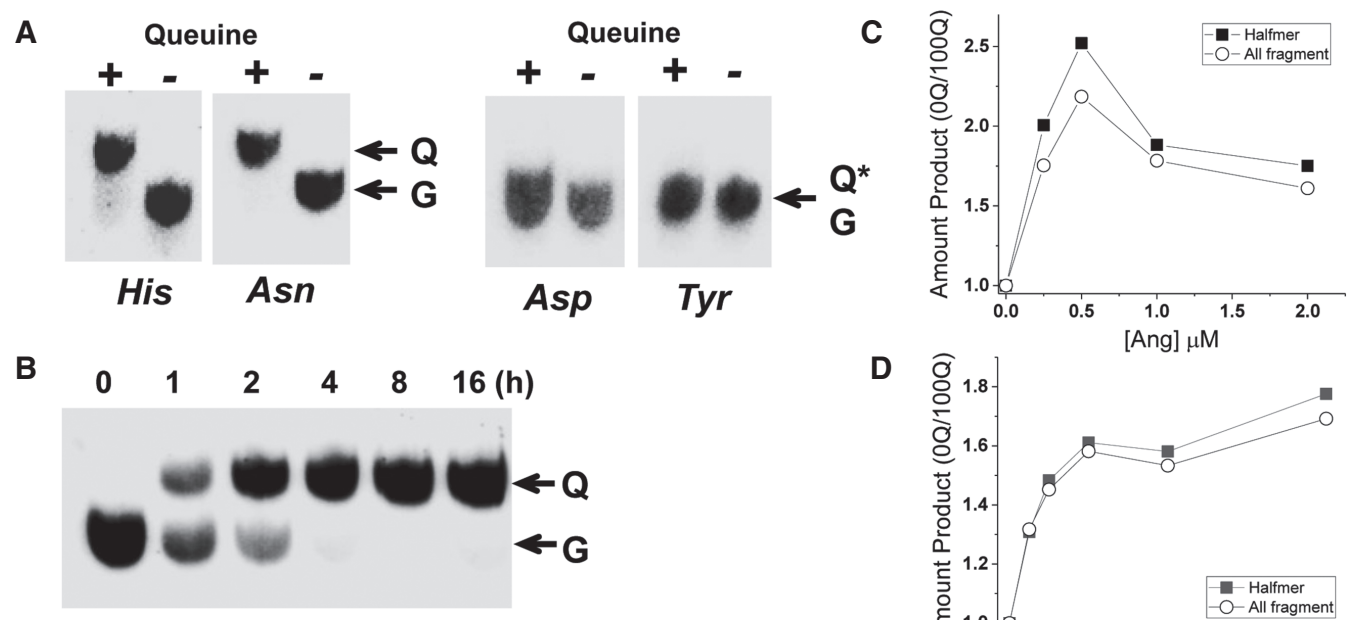

D
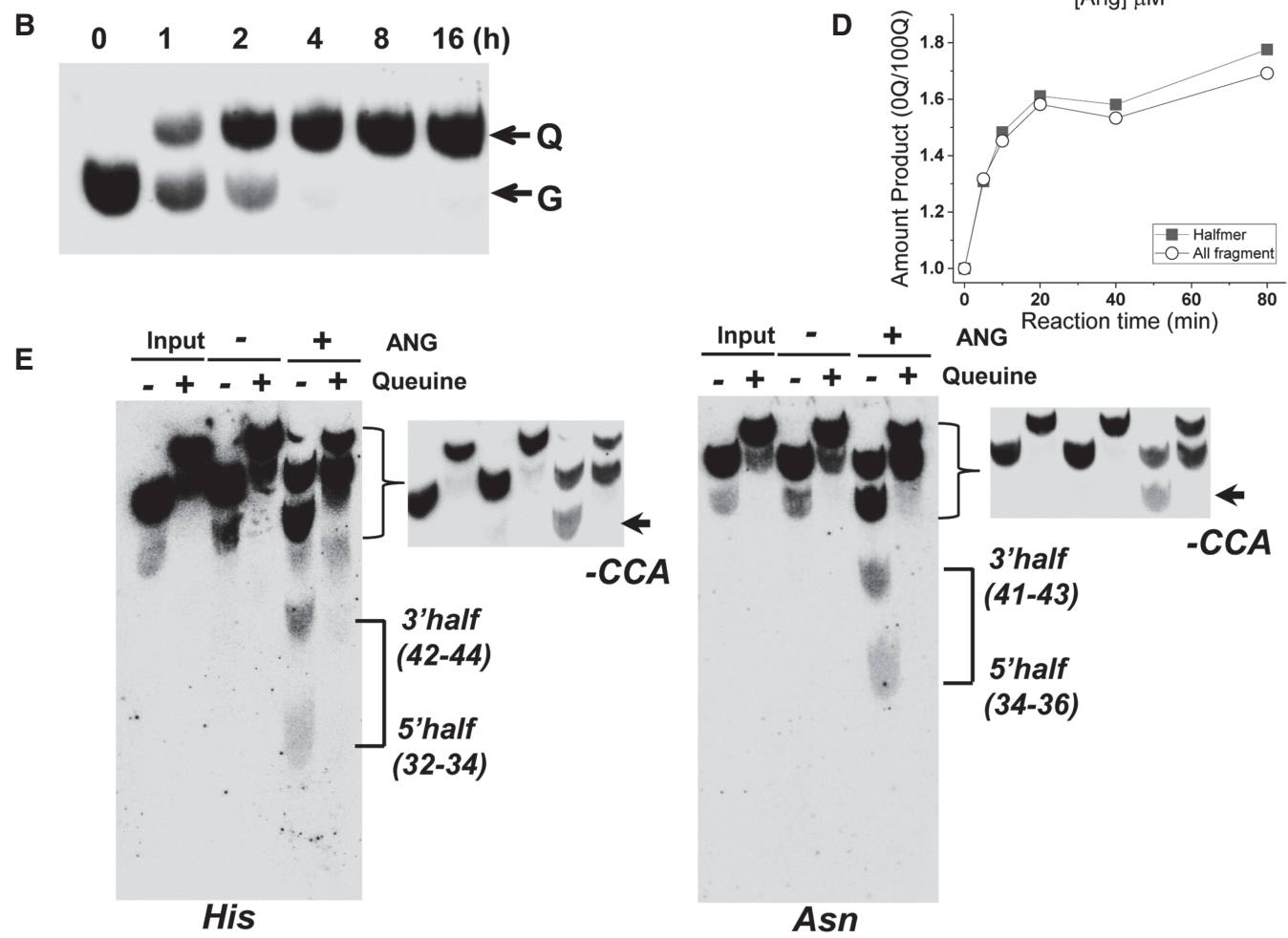

FIGURE 1. Q modification inhibits angiogenin cleavage in vitro. (A) Northern blot analysis of total RNAs isolated from 0Q, 100Q HEK293T cells probed against tRNA ${ }^{\text {His }}, t^{2} N A^{\text {Asn }}$, tRNA ${ }^{\text {Asp }}$, and tRNA ${ }^{\text {Tyr }}$ separated by APB-containing gels. $\mathrm{Q}, \mathrm{Q}^{*}$, and $\mathrm{G}$ indicate tRNA with Q34, glycosylated $\mathrm{Q} 34$ and G34, respectively. (B) Appearance of $\mathrm{Q}$ modification for tRNA ${ }^{\text {Asn }}$ starting from the addition of queuine to HEK293T $0 \mathrm{Q}$ cells. $\mathrm{Q}$ and $\mathrm{G}$ indicate tRNA with $Q 34$ and $G 34$, respectively. $(C, D)$ Comparative amount of angiogenin cleavage products upon varying the angiogenin concentration $(C)$ or reaction time $(D)$ of total tRNA isolated from 00 and 1000 HEK293T cells. tRNAs were $5^{\prime}{ }^{32}$ P-labeled, so the products can be identified by size. Comparison includes either only tRNA halfmer products corresponding to cleavage in the anticodon loop or all fragments derived from cleavage anywhere in the tRNA body. (E) Northern blot analysis of tRNA cleavage by angiogenin separated by APB-containing gels using the tRNA ${ }^{\text {His }}$ probe on the left and tRNA ${ }^{\text {Asn }}$ probe on the right. Northern blot detected both $5^{\prime}$ and $3^{\prime}$ cleavage product in the anticodon loop; these halfmers in the $0 \mathrm{O}$ sample are indicated by connecting lines on the right, and the size of the products is shown in parentheses. The product near the full-length likely corresponds to angiogenin cleavage of the $3^{\prime}$ CCA tail; these are indicated by an arrow and -CCA on the right. A high contrast image of this portion is also shown for better visualization. Quantitation of these products is shown in Supplemental Table S1. Q-containing tRNA fragments are shifted in the 1000 sample.

products from tRNAs isolated from 00 over 1000 cells. We found that the amount of both all and halfmer cleavage products was always lower using total tRNAs from 1000 cells compared to those from 00 cells, either at varying concentration of angiogenin from $0.25-2 \mu \mathrm{M}$ or over a time course from 5-80 min. To specifically examine the cleavage products for the Q-modified tRNA ${ }^{\text {His }}$ and tRNA $^{\text {Asn }}$, we performed northern blot analysis for these tRNAs (Fig. 1E). We found three products for both tRNAs. The two shorter ones correspond to the $5^{\prime}$ and $3^{\prime}$ halfmers of the angiogenin cleavage in the anticodon loop. Both halfmer products were stable in vitro and detected by the same northern probe we used here. We found an approximately twofold decrease in the halfmer products for 1000 tRNAs versus 00 tRNAs for tRNA ${ }^{\text {His }}$ and an approximately ninefold decrease for tRNA ${ }^{\text {Asn }}$ (Supplemental Table S1). The longest product close to the full-length tRNA corresponds to the known, in vitro angiogenin cleavage of $3^{\prime} \mathrm{CCA}$ of the tRNAs reported previously (Czech et al. 2013). The amount of this product was 
increased by $\sim 1.5$-fold for 1000 tRNAs over those for 00 tRNAs which was in the opposite direction as the halfmer products (Supplemental Table S1). These results indicate that $\mathrm{Q}$ modification can directly protect cognate tRNA ${ }^{\mathrm{His}}$ and RRNA $^{\text {Asn }}$ from angiogenin cleavage in the anticodon loop in vitro.

\section{Q modification and full-length tRNA abundance and tRNA fragments in vivo}

To examine the cellular effects of $\mathrm{Q}$ modification on tRNA, we performed demethylase tRNA-seq (DM-tRNA-seq [Zheng et al. 2015]) to quantitatively compare the levels of all full-length tRNAs. We previously developed the DMtRNA-seq method that removes many Watson-Crick face base methylations prior to cDNA synthesis by a processive, thermophilic group II intron reverse transcriptase to enable accurate quantitation of full-length tRNAs. We found by comparative analysis that 00 and 1000 cells have very similar tRNA expression profiles (Fig. 2A), indicating that $Q$ modification did not change the levels of full-length tRNAs.

To examine the effect of $Q$ modification on tRNA fragment profiles, we gel purified small RNAs in the size range of 20-60 nucleotides from 00 and 1000 HEK293T cells. To reduce the interference of Watson-Crick face methylations for the quantitative comparison among the tRNA fragments, we again treated this small RNA pool with the AlkB enzymes, which can efficiently remove $m^{1} A, m^{1} G$, $\mathrm{m}^{3} \mathrm{C}$ and in part $\mathrm{m}^{2}{ }_{2} \mathrm{G}$ (Clark et al. 2016). Removal of these modifications should be more efficient for tRNA fragments than full-length tRNA due to the loss of tRNA structure in tRNA fragments (Cozen et al. 2015). We found that HEK293T cells already contained a considerable amount of tRNA fragments in the absence of stress (Fig. 2B), on the order of $\sim 1 \%$ relative to total full-length tRNAs (see below). At this time we do not know which and how much of these fragments were derived from angiogenin specifically. Since angiogenin is inhibited by its protein inhibitor RNH1 in the absence of stress (Yamasaki et al. 2009), it is conceivable that many fragments were produced by other ribonucleases in cells. This may explain that in the comparative analysis of individual tRNA fragments within each sample, fragments from several tRNAs that do not contain Q-modification (GInCTG, LysCTT, ValAAC) were present at higher levels in 1000 than in 00 cells (Fig. 2B).

On the other hand, Q-modified cognate tRNAs consistently showed higher fragment levels in 00 cells versus 1000 cells. Among these, tRNA ${ }^{\text {His }}$ and tRNA Asp fragments were present at higher levels than tRNA ${ }^{A s n}$ and $t R N A^{T y r}$, and the levels for both were also substantially higher in 00 cells (Fig. 2B; Supplemental Fig. S3A). We further analyzed the tRNA fragment pattern of the Q-modified cognate tRNAs (Fig. 2C; Supplemental Fig. S3). Unlike in vitro conditions where both $5^{\prime}$ and $3^{\prime}$ tRNA halfmer fragments are stable (Fig. 1E), only one of the two products are generally stable in cells. In $0 \mathrm{O}$ cells, tRNA ${ }^{\text {His }}$ fragments were primarily derived from cleavage near the $5^{\prime}$ end of the anticodon loop, with the major product encompassing the $5^{\prime}$ end to nucleotides 30-31, consistent with those observed in other cell lines in previous studies (Honda et al. $2015,2017)$. The same $5^{\prime}$ fragments were significantly reduced in 1000 cells which also contained slightly more fragments encompassing the middle portion of the tRNA (Fig. 2C; Supplemental Fig. S3B). tRNA Asn fragments were present at a lower level than tRNA ${ }^{\text {His }}$, and they were enriched from cleavage near the $3^{\prime}$ end of the anticodon loop (Fig. 2D; Supplemental Fig. S3C).

One question remained whether the differential amount of tRNA fragments among Q-modified cognate tRNAs may also be derived from another modification in the same tRNA that is dependent on the Q-modification. One precedent for this is the tRNA ${ }^{\text {Asp }}$ in $S$. pombe where Q34 influences the $\mathrm{m}^{5} \mathrm{C} 38$ modification in the anticodon loop; $m^{5} \mathrm{C} 38$ is known to reduce tRNA fragment generation for several tRNAs in cells (Schaefer et al. 2010). Ideally one would quantitatively compare the fractions of all other modifications in the Q-modified cognate tRNAs from 00 and 1000 cells. This approach however is beyond the scope of this work; therefore we adapted our DMtRNA-seq approach where several Watson-Crick modifications can be quantitatively compared between two samples using mutation and stop signatures generated by the RT enzyme during cDNA synthesis (Supplemental Fig. S4; Clark et al. 2016). In tRNA ${ }^{\text {His }}$, two modifications can be measured this way that include the $\mathrm{m}^{1} \mathrm{~A} 58$ in the $T$ loop, and a newly found $m^{1} G 37$ (Clark et al. 2016) in the anticodon loop. In tRNA ${ }^{\text {Asn }}$, the four measurable modifications include $\mathrm{m}^{1} \mathrm{~A} 58, \mathrm{~m}^{2}{ }_{2} \mathrm{G} 26$ between $\mathrm{D}$ and anticodon stems, $a c p^{3} U$ in the $D$ loop, and $m^{1} G 9$ between acceptor and D stems. In all cases, the mutation plus stop fractions at these positions are identical or very similar in 00 and 1000 tRNAs, suggesting that $Q$ modification does not significantly change the patterns of other modifications in these cognate tRNAs.

\section{Q modification and tRNA cleavage under stress and angiogenin treatment in vivo}

To examine the role of $\mathrm{Q}$ modification in generating tRNA fragments in cells under stress, we treated HEK293T and HeLa cells with sodium arsenite which was known to induce tRNA cleavage by ribonucleases (Yamasaki et al. 2009; Ivanov et al. 2011), or directly treated cells with recombinant human angiogenin protein (Fig. 3). In HEK293T cells (Fig. 3A), we found that small RNAs in the size range corresponding to tRNA halfmers increased in the arsenite stress and upon angiogenin treatment relative to the amount of total full-length tRNA. In HeLa cells devoid of $\mathrm{Q}$ modifications (Supplemental Fig. S5), we found that the amount of these small RNAs increased 


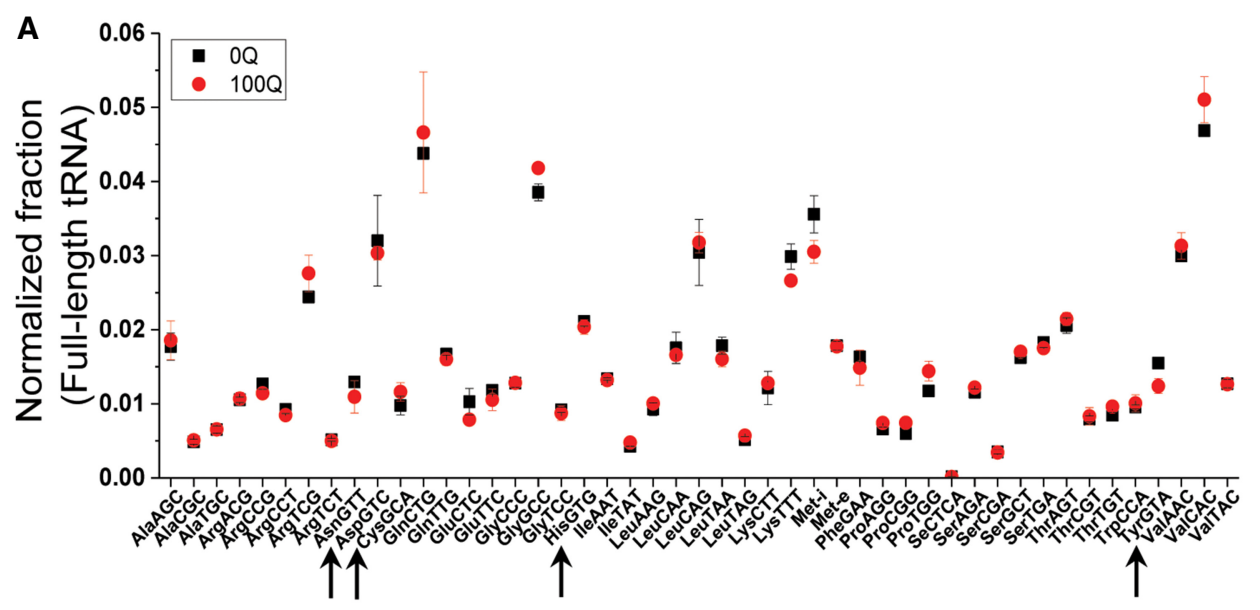

B

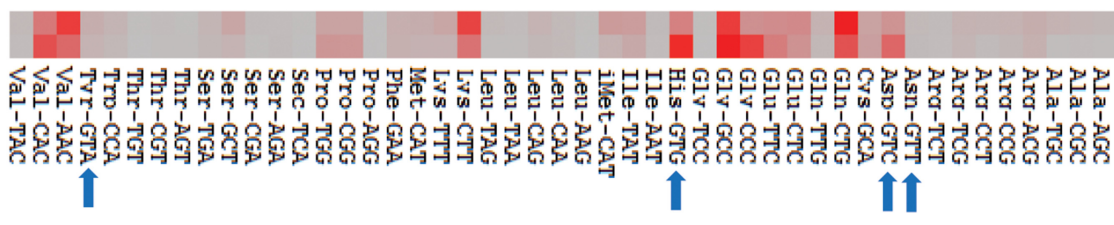

$100 Q$

OQ
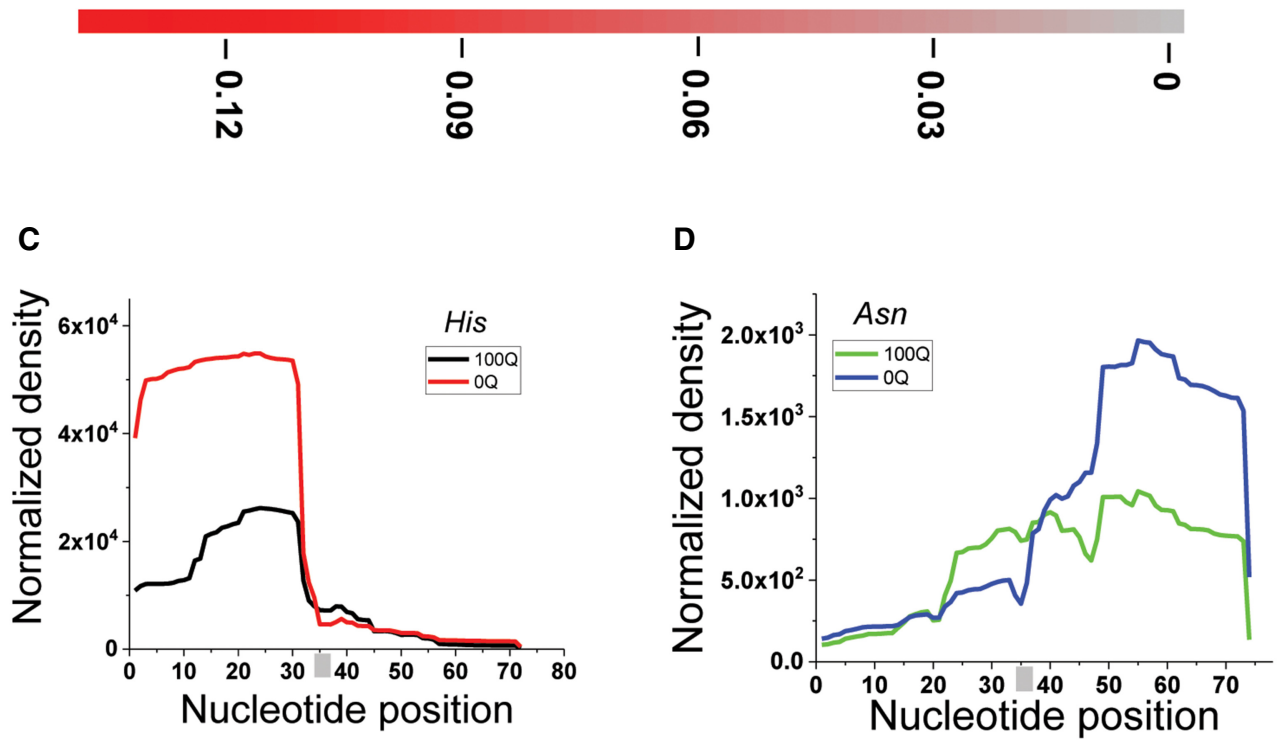

FIGURE 2. Q modification and tRNA fragments in vivo by RNA-seq. (A) Comparison of the tRNA isoacceptor family abundance of 00 and 1000 HEK293T cells by DM-tRNA-seq. Arrows indicate the four Q-modified cognate tRNAs. The total number of assigned tRNA reads is set to 1 in each sample, and the fraction of each tRNA isoacceptor is shown. (B) Heatmap of tRNA fragment abundance at the isoacceptor family level. The amount of all tRNA fragment products of all sizes in each sample are added together and set as 1; shown are the fractions of individual tRNA isoacceptors. Arrows indicate the four Q-modified cognate tRNAs. The scale bar shows the fraction tRNA fragments in the heatmap. $(C, D)$ tRNA ${ }^{\text {His }}$ and tRNA ${ }^{\text {Asn }}$ fragment coverage from $0 \mathrm{Q}$ and $100 \mathrm{Q}$ HEK293T cells. The anticodons (GTG for tRNA ${ }^{\text {His }}$, and GTT for tRNA ${ }^{\text {Asn }}$ ) are indicated by a gray bar.

substantially under the arsenite stress, but not upon the addition of angiogenin (Fig. 3B). The cell line dependent result may be derived from differential ribonuclease activities in these cells. Northern blots of these same samples (Fig. 3C,D) showed that tRNA halfmer fragments derived specifically from the Q-modified cognate tRNA ${ }^{\text {His }}$ and tRNA ${ }^{A s n}$ increased under all conditions. Importantly, the amount of these tRNA fragments was always higher in $0 \mathrm{Q}$ cells compared to $100 \mathrm{Q}$ cells (Fig. $3 \mathrm{E}$ ).

\section{Concluding remarks}

Taken together, our results indicate that queuosine tRNA modification directly protects the cognate tRNAs against 


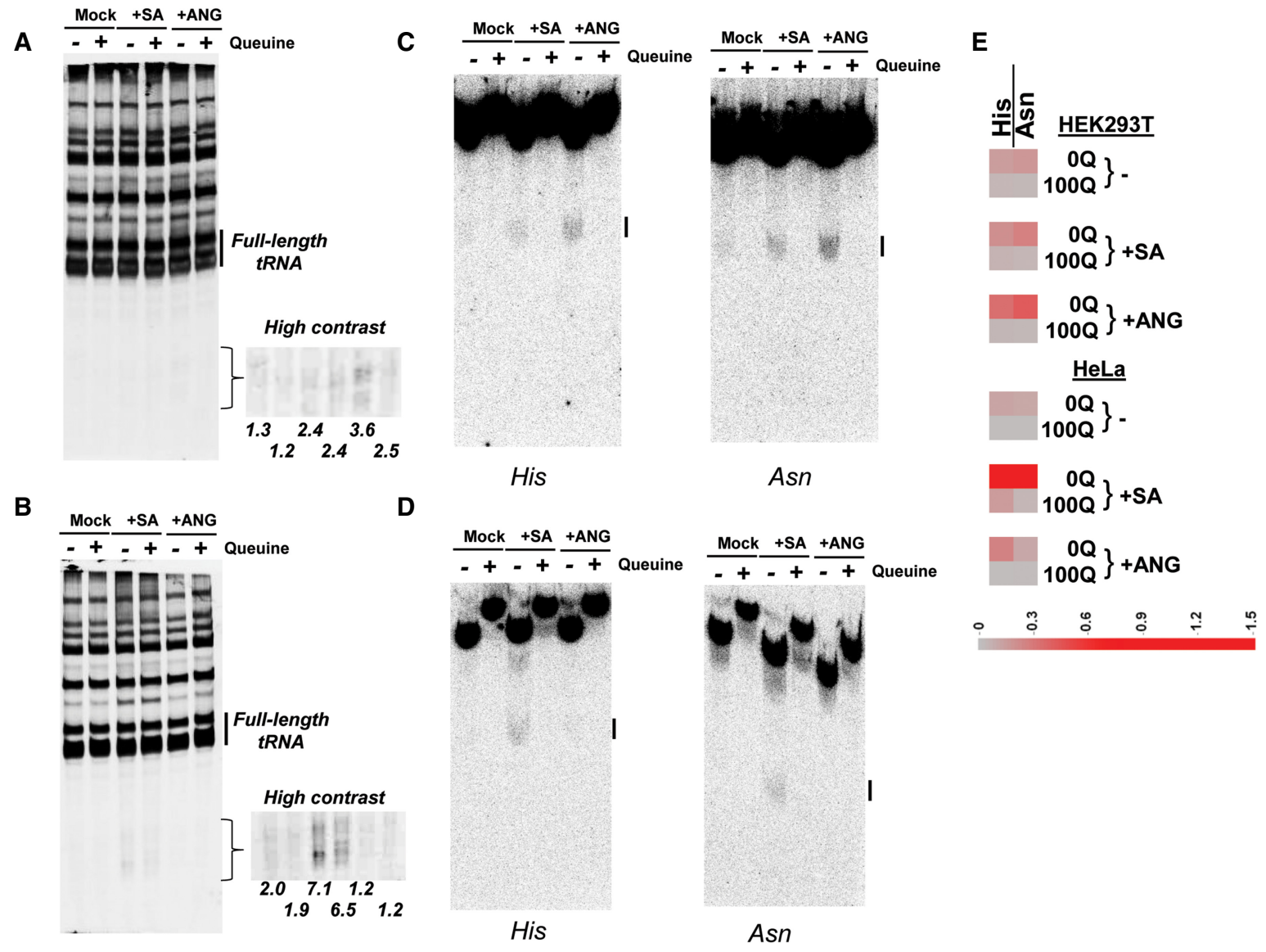

FIGURE 3. Q modification protects cognate tRNA cleavage under arsenite stress and angiogenin treatment in cells. (A) Total small RNA fragment analysis of total cellular RNA isolated from $0 \mathrm{Q}$ and 1000 HEK293T cells by SYBR gold staining under conditions of no stress (Mock), plus sodium arsenite (SA), plus recombinant human angiogenin protein (ANG). Total RNA was analyzed on 10\% denaturing PAGE containing 7 M urea. Fulllength tRNA bands are indicated by a bar on the right. The size region corresponding to tRNA halfmers is also shown in higher contrast on the right. Percentages of total tRNA halfmer sized fragments relative to full-length tRNA are shown beloweach lane. (B) Same as A for HeLa cells. (C) Northern blot analyses of the same samples in A using tRNA ${ }^{\text {His }}$ and tRNA ${ }^{A s n}$ probes separated by APB-containing gels. tRNA fragments corresponding to the halfmers are indicated by a bar on the right. (D) Same as $C$ for HeLa cells. ( $E$ ) Heatmap of tRNA ${ }^{\text {His }}$ and tRNA ${ }^{\text {Asn }}$ halfmer fragment products for $0 \mathrm{Q}$ and 1000 cells. The scale bar shows the percent product under these conditions relative to full-length tRNA on the same northern blot.

ribonuclease cleavage and alters the tRNA fragment derived small RNA pools in human cells. tRNA fragments are heterogeneous in size, composition, biogenesis, and function (Fu et al. 2009; Yamasaki et al. 2009; Phizicky and Hopper 2010) and play important roles in cell physiology and human health and disease (Anderson and Ivanov 2014; Goodarzi et al. 2015; Gapp and Miska 2016). Like the known function for many fragments from tRNAs not modified with $\mathrm{Q}, \mathrm{Q}$ modification dependent tRNA fragments may also play a role in cellular stress response, although this biological hypothesis was not addressed here. Previous studies showed that tRNA Q modification levels could be lower in cancer cells and tRNA $Q$ hypomodification could affect cell proliferation and malignancy (Pathak et al. 2005; Vinayak and Pathak 2009). Future investigation will examine what roles the tRNA fragments derived from tRNA ${ }^{\text {His }}$ and tRNA ${ }^{\text {Asn }}$ play under different cellular contexts.
In summary, we show here a previously unappreciated biological aspect of tRNA $\mathrm{Q}$ modification in human cells which complements its known roles in translational control through codon-anticodon interaction. The level and pattern of Q-mediated tRNA fragments may serve as markers for the status of cellular stress, nutrient deprivation and diseases.

\section{MATERIALS AND METHODS}

\section{Cell culture and generation of Q-depleted cell lines}

Human embryonic kidney HEK293T cells (CRL-11268) and human cervical cancer HeLa cells (CCL-2) from ATCC were grown in Dulbecco's modified Eagle's medium supplemented with $10 \%$ dialyzed fetal bovine serum (US origin, Life Technologies), and 1\% penicillin-streptomycin. Cells were passaged at the confluency of 70\%-90\% for $\sim 10$ passages to generate Q-depleted cell lines 
(designated as 00 cells). Total RNA was isolated using the TRIzol method, and the tRNA queuosine modification level was determined by northern blot analysis with specific tRNA probes as described below. 00 cell lines proliferated normally under standard culture conditions, and were stocked for subsequent experiments. To fully restore tRNA Q modification, Q-depleted cells were supplemented with queuine (Toronto Research Chemicals) at $1 \mu \mathrm{M}$ for $24 \mathrm{~h}$ (designated as 1000 cells).

\section{In vitro tRNA angiogenin cleavage assay}

In vitro angiogenin cleavage assay was performed in accordance with a previous study (Czech et al. 2013). Briefly, to prepare the tRNA substrates, total tRNAs from 00 and1000 HEK293T cells were $5^{\prime}{ }^{32} \mathrm{P}$-labeled and gel purified. Nonradioactive, gel purified tRNAs $(1 \mu \mathrm{g} / \mu \mathrm{L})$ from corresponding 00 and 1000 cells were spiked with respective ${ }^{32} \mathrm{P}$-labeled tRNAs in $30 \mathrm{mM}$ Tris $\mathrm{HCl}, \mathrm{pH}$ 7.4, $30 \mathrm{mM} \mathrm{NaCl}$, heated at $90^{\circ} \mathrm{C}$ for $2 \mathrm{~min}$ and then incubated at room temperature for $3 \mathrm{~min}$. $\mathrm{MgCl}_{2}$ was added to a final concentration of $2 \mathrm{mM}$, and the sample was further incubated for $5 \mathrm{~min}$ at $37^{\circ} \mathrm{C}$. Recombinant human angiogenin (R\&D systems) was added to a final concentration of $0-2 \mu \mathrm{M}$ to the reaction and incubated at $37^{\circ} \mathrm{C}$ for the indicated period of time. The reactions were stopped by adding $2 \times$ urea loading buffer ( $9 \mathrm{M}$ urea, $100 \mathrm{mM}$ EDTA), and the full-length tRNAs and tRNA fragments were separated on a denaturing 10\% PAGE gel followed by exposure to phosphorimaging plates. Band intensity of fraction products after angiogenin digestion was quantified using Imager software.

\section{tRNA fragments generation under stress conditions and angiogenin treatment in vivo}

00 HEK293T cells and HeLa cells were grown in Dulbecco's modified Eagle's medium supplemented with $10 \%$ dialyzed fetal bovine serum and $1 \%$ penicillin-streptomycin. At the confluency of $\sim 50 \%$, half of the cells were supplemented with or without queuine at $1 \mu \mathrm{M}$ for $24 \mathrm{~h}$ to generate 1000 cells. Subsequently, $\mathrm{OQ}$ and 1000 cells were treated with or without stress conditions. For angiogenin (ANG) treatment, cells were treated with recombinant human angiogenin (R\&D systems) at $1 \mu \mathrm{g} / \mathrm{mL}$ for $2 \mathrm{~h}$ at $37^{\circ} \mathrm{C}$. For oxidative stress, cells were treated with $500 \mu \mathrm{M}$ sodium arsenite (SA) for $2 \mathrm{~h}$ at $37^{\circ} \mathrm{C}$. The stress conditions were the same for $0 \mathrm{Q}$ and $100 \mathrm{Q}$ HeLa cells as for HEK293T cells. Total RNAs were extracted by the mirVana miRNA Isolation Kit and separated on $10 \%$ denaturing PAGE, and stained by SYBR gold staining to visualize tRNA fragments. $Q$ modification levels and tRNA fragments were detected by northern blot analysis as described below.

\section{Determination of $Q$ modification levels in tRNA ${ }^{\text {His }}$ and tRNA ${ }^{\text {Asn }}$ using 3-acrylamidophenylboronic acid (APB) gel and northern blot analysis}

This method was based on the protocol developed previously (Igloi and Kossel 1985; Zaborske et al. 2014). Total RNA was deacylated by incubating in $100 \mathrm{mM}$ Tris- $\mathrm{HCl}(\mathrm{pH}$ 9.0) for 30 min at $37^{\circ} \mathrm{C}$. Deacylated RNA samples were combined with an equal volume of denaturing $2 \times$ gel loading buffer containing $9 \mathrm{M}$ urea, $100 \mathrm{mM}$ EDTA. Samples were loaded onto denaturing $10 \%$ polyacrylamide gels containing 5\% 3-Acrylamidophenylboronic acid (Frontier Scientific), and gel electrophoresis was run at $4^{\circ} \mathrm{C}$ in TAE buffer. RNA was transferred onto Hybond-XL membrane (GE Healthcare) using a vacuum gel dryer for $2 \mathrm{~h}$ at $80^{\circ} \mathrm{C}$. The membrane was then washed twice for 30 min each in the hybridization buffer (20 mM phosphate, $\mathrm{pH} 7.2,300 \mathrm{mM} \mathrm{NaCl}, 1 \%$ SDS), followed by hybridization with $5^{\prime}{ }^{32} \mathrm{P}$-labeled oligonucleotide probes of four Q-containing tRNAs in the hybridization buffer for $16 \mathrm{~h}$ at $60^{\circ} \mathrm{C}$. Membranes were washed twice for $30 \mathrm{~min}$ each in a solution containing $20 \mathrm{mM}$ phosphate, $\mathrm{pH} 7.2,300 \mathrm{mM} \mathrm{NaCl}$, $2 \mathrm{mM}$ EDTA, and $0.1 \%$ SDS and exposed to phosphorimaging plates. Band intensity was quantified using Imager software. Oligonucleotide probe sequences were: tRNA ${ }^{\text {His. }}$ 5'TGCCGTGA CTCGGATTCGAACCGAGGTTGCTGCGGCCACAACGCAGAG TACTAACCACTATACGATCACGGC; tRNA ${ }^{\text {Asn: }}$ 5'CGTCCCTGGG $^{\prime}$ TGGGCTCGAACCACCAACCTTTCGGTTAACAGCCGAACGCG CTAACCGATTGCGCCACAGAGAC; tRNA ${ }^{\text {Asp: }} 5^{\prime}$ CTCCCCGTCG GGGAATCGAACCCCGGTCTCCCGCGTGACAGGCGGGGATA CTCACCACTATACTAACGAGGA; tRNA ${ }^{\text {Tyr }}$ : 5'TCCTTCGAGCCG GASTCGAACCAGCGACCTAAGGATCTACAGTCCTCCGCTCTA CCARCTGAGCTATCGAAGG.

\section{Identification of glycosylated Q-tRNA modifications by HPLC and mass spectrometry}

Total RNA extracted from 1000 cells was used to purify tRNA ${ }^{\text {Asp }}$ and tRNA ${ }^{T y r}$ which are known to be further modified to mannose$\mathrm{Q}$ and galactose- $\mathrm{Q}$, respectively. $160 \mu \mathrm{g}$ of total RNA was hybridized with 160 pmole $5^{\prime}$ biotin-labeled oligos of the same sequences as the northern blot probes above for tRNA ${ }^{\text {Asp }}$ and tRNA ${ }^{\mathrm{Tyr}}$ in $2 \mathrm{XSC}$ at $16^{\circ} \mathrm{C}$ for $16 \mathrm{~h}$, followed by incubation with Dynabeads M-280 streptavidin beads (Invitrogen) at room temperature for $1 \mathrm{~h}$. The RNAs were released from beads by DNase I digestion at $37^{\circ} \mathrm{C}$ for $30 \mathrm{~min}$, followed by acid phenol extraction $(\mathrm{pH} 4.5)$ and ethanol precipitation. RNAs were dissolved in water and the concentration was determined by UV absorbance using Nanodrop.

Purified tRNA ${ }^{\text {Asp }}$ or tRNA ${ }^{\text {Tyr }}$ were digested in $45 \mu \mathrm{L}$ containing $11 \mathrm{mM}$ Tris- $\mathrm{HCl}, \mathrm{pH}$ 7.5, $1.1 \mathrm{mM}$ EDTA, $\mathrm{pH}$ 8.0, and $89 \mathrm{ng} / \mu \mathrm{L}$ RNase $\mathrm{A}$ and $22 \mathrm{ng} / \mu \mathrm{L}$ nuclease $\mathrm{T} 1$ at $37^{\circ} \mathrm{C}$ for $1 \mathrm{~h}$. $160 \mu \mathrm{l}$ water was added, the mixture spun at highest speed for $10 \mathrm{~min}$ and transferred to a HPLC vial. A total of $200 \mu \mathrm{l}$ was injected, and the HPLC gradient was $0 \%-15 \%$ acetonitrile in $0.05 \mathrm{M}$ TEAA in $30 \mathrm{~min}$. All peaks except for those of mononucleotide 3'-phosphates were collected. After speedvac, the RNA fragments were subjected to digestion with $0.044 \mathrm{U} / \mu \mathrm{L}$ nuclease P1 (Sigma) in $25 \mathrm{mM} \mathrm{NaCl}, 2.5 \mathrm{mM} \mathrm{ZnCl}_{2}, \mathrm{pH} 5.5$ at $37^{\circ} \mathrm{C}$ for $2 \mathrm{~h}$ to generate the corresponding $5^{\prime}$-phosphate. The reaction mixture was diluted to $500 \mu \mathrm{L}$ and spun at highest speed for $10 \mathrm{~min}$. The supernatant was transferred to a new vial and injected to HPLC eluting with $0 \%-12 \%$ acetonitrile in 0.05 $M$ TEAA in 30 min while collecting each peak. Absorbance spectra for each peak was taken and compared to the known absorbance profile of Q-modified nucleotides (Costa et al. 2004). After speedvac, the pellet was dissolved in $10 \mu \mathrm{L}$ water, and $2 \mu \mathrm{L}$ were mixed with THAP matrix followed by MALDI MS analysis. 


\section{Full-length tRNA sequencing}

High-throughput tRNA sequencing of $0 \mathrm{Q}$ and 1000 HEK293T cells was performed using the demethylase-tRNA-seq (DMtRNA-seq) method according to the published protocol (Zheng et al. 2015; Evans et al. 2017).

\section{tRNA fragment sequencing}

tRNA fragment sequencing was adapted from a previously reported method with the added step of AlkB demethylase treatment to remove Watson-Crick face methyl modifications (Zheng et al. 2015; Evans et al. 2017). Total RNAs were extracted from 00 and 1000 HEK293T cells with the mirVana miRNA Isolation Kit. $5^{\prime}$ and $3^{\prime}$ tRNA fragments in the size range of 20-60 nt were gel-size selected, and RNAs were eluted by incubation with crush and soak buffer ( $50 \mathrm{mM} \mathrm{KOAc} / 200 \mathrm{mM} \mathrm{KCl}, \mathrm{pH} 7.0)$ at $4^{\circ} \mathrm{C}$ overnight. The eluted RNA was dissolved in water. Demethylation reaction was performed under previously optimized conditions (Zheng et al. 2015; Evans et al. 2017). A total of $100 \mu$ l of reaction mixture containing $0.5 \mu \mathrm{g}$ of isolated small RNA ( 40 pmole) was treated with $2 \times$ molar ratio of wild-type AlkB enzyme ( 80 pmole) and $4 \times$ molar ratio of $\mathrm{D} 135 \mathrm{~S}$ mutant ( 160 pmole). The reaction buffer contained $300 \mathrm{mM} \mathrm{KCl}, 2 \mathrm{mM} \mathrm{MgCl} 2,50 \mu \mathrm{M}$ of $\left(\mathrm{NH}_{4}\right)_{2} \mathrm{Fe}$ $\left(\mathrm{SO}_{4}\right)_{2} \cdot 6 \mathrm{H}_{2} \mathrm{O}, 300 \mu \mathrm{M}$ 2-ketoglutarate (2-KG), $2 \mathrm{mM}$ L-ascorbic acid, $50 \mu \mathrm{g} / \mathrm{mL}$ BSA, $50 \mathrm{mM}$ MES, pH 5.0. The reaction was incubated for $2 \mathrm{~h}$ at room temperature and quenched by the addition of $5 \mathrm{mM}$ EDTA final concentration. After phenol-chloroform extraction, $1 / 10$ volume of $3 \mathrm{M} \mathrm{NaOAc/HOAc}, \mathrm{pH} 4.8$ was added and RNAs were recovered by ethanol precipitation.

Precipitated RNAs were deacylated in $20 \mu \mathrm{L} 0.1 \mathrm{M}$ Tris- $\mathrm{HCl}, \mathrm{pH}$ 9.0 at $37^{\circ} \mathrm{C}$ for $30 \mathrm{~min}$. Twenty microliters buffer containing $0.1 \mathrm{M}$ Tris- $\mathrm{HCl}, \mathrm{pH} 7.0,20 \mathrm{mM} \mathrm{MgCl} 2$ and $2 \mathrm{U} / \mu \mathrm{L}$ T4 kinase (NEB) was added and the mixture was incubated at $37^{\circ} \mathrm{C}$ for another 30 min to remove the $3^{\prime}$ and $2^{\prime}, 3^{\prime}$ cyclic phosphates of the tRNA fragments (Honda et al. 2015, 2017). RNAs were extracted using acidic Phenol/ $\mathrm{CHCl}_{3}(\mathrm{pH} 4.5)$ with $0.3 \mathrm{M} \mathrm{NaOAc} / \mathrm{HOAc}, \mathrm{pH} 4.8$, followed by ethanol precipitation. Directional ligation of adapters, cDNA generation, and PCR amplification were performed using the TruSeq Small RNA Sample Prep Kit (Illumina) according to the manufacturer's protocol. The amplified cDNAs were sequenced using Illumina HiSeq 2000 in the Genomics Core at the University of Chicago.

\section{Sequencing data analysis}

For full length tRNA sequencing, all libraries were sequenced on an Illumina HiSeq 1000 with paired-end mapping using read lengths of $100 \mathrm{bp}$. Standard quality control via FastQC was performed after sequencing and also after read processing. Reads were processed using Trimmomatic v0.32 to remove the standard Illumina adapter sequence followed by subsequent trimming using custom Python scripts to remove demultiplexing artifacts, primers, and trim the extended adapter. This second trimming step ensures that reads are not over-trimmed by Trimmomatic to ensure fidelity of the $3^{\prime}$ end of the raw reads. The resultant trimmed sequences were then aligned to the library using Bowtie 1.0 with sensitive options (-- k 1 -v 3 -best -strata). Sequencing reads were aligned to a modified tRNA hg19 ge- nome file, containing nuclear-encoded tRNAs, mitochondrial-encoded tRNAs, and non-Homo sapiens tRNAs as standards.

For tRNA fragment sequencing, reads were mapped using bowtie version 1.0 on human tRNA sequences, provided by the genomic tRNA database (http://gtrnadb.ucsc.edu/genomes/ eukaryota/Hsapi19/hg19-tRNAs.fa [Chan and Lowe 2016]). Only one copy of multiple identical tRNA sequences was retained for Bowtie's index files, for a total of $n=419$ unique tRNA sequences. Pileup plots were derived from mapped reads using samtools version 0.1.19 (Li et al. 2009), and allowed to quantify tRNAs in the following manner: Reads that uniquely map to one tRNA were used to randomly assign reads that map to multiple tRNAs. The random assignment is such that it is proportional to the number of unique hits each tRNA has. For each sample, tRNA quantification was normalized with the help of the normalize.quantiles function of the "preprocessCore" R package (Bolstad et al. 2003).

\section{SUPPLEMENTAL MATERIAL}

Supplemental material is available for this article.

\section{DATA DEPOSITION}

The full-length tRNA and tRNA fragment sequencing data have been deposited in NCBI database under GEO accession number GSE102570.

\section{ACKNOWLEDGMENTS}

This work was supported by the Department of Defense/ Congressionally Directed Medical Research Programs (DoD/ CDMRP; BC160450 to T.P.) and the National Institutes of Health/National Institute of Diabetes and Digestive and Kidney Diseases (NIH/NIDDK; K01 DK111764 to X.Y.W.).

Received April 27, 2018; accepted June 26, 2018.

\section{REFERENCES}

Anderson P, Ivanov P. 2014. tRNA fragments in human health and disease. FEBS Lett 588: 4297-4304.

Bolstad BM, Irizarry RA, Astrand M, Speed TP. 2003. A comparison of normalization methods for high density oligonucleotide array data based on variance and bias. Bioinformatics 19: 185-193.

Chan PP, Lowe TM. 2016. GtRNAdb 2.0: an expanded database of transfer RNA genes identified in complete and draft genomes. Nucleic Acids Res 44: D184-D189.

Clark WC, Evans ME, Dominissini D, Zheng G, Pan T. 2016. tRNA base methylation identification and quantification via high-throughput sequencing. RNA 22: 1771-1784.

Costa A, Pais de Barros JP, Keith G, Baranowski W, Desgres J. 2004. Determination of queuosine derivatives by reverse-phase liquid chromatography for the hypomodification study of Q-bearing tRNAs from various mammal liver cells. J Chromatogr B Analyt Technol Biomed Life Sci 801: 237-247.

Cozen AE, Quartley E, Holmes AD, Hrabeta-Robinson E, Phizicky EM, Lowe TM. 2015. ARM-seq: alkB-facilitated RNA methylation sequencing reveals a complex landscape of modified tRNA fragments. Nat Methods 12: 879-884. 
Czech A, Wende S, Morl M, Pan T, Ignatova Z. 2013. Reversible and rapid transfer-RNA deactivation as a mechanism of translational repression in stress. PLoS Genet 9: e1003767.

Ehrenhofer-Murray AE. 2017. Cross-talk between Dnmt2-dependent tRNA methylation and queuosine modification. Biomolecules 7: E14.

El Yacoubi B, Bailly M, de Crecy-Lagard V. 2012. Biosynthesis and function of posttranscriptional modifications of transfer RNAs. Annu Rev Genet 46: 69-95.

Emara MM, Ivanov P, Hickman T, Dawra N, Tisdale S, Kedersha N, Hu GF, Anderson P. 2010. Angiogenin-induced tRNA-derived stress-induced RNAs promote stress-induced stress granule assembly. J Biol Chem 285: 10959-10968.

Endres L, Dedon PC, Begley TJ. 2015. Codon-biased translation can be regulated by wobble-base tRNA modification systems during cellular stress responses. RNA Biol 12: 603-614.

Evans ME, Clark WC, Zheng G, Pan T. 2017. Determination of tRNA aminoacylation levels by high-throughput sequencing. Nucleic Acids Res 45: e133.

Fergus C, Barnes D, Alqasem MA, Kelly VP. 2015. The queuine micronutrient: charting a course from microbe to man. Nutrients 7: 2897-2929.

Fu H, Feng J, Liu Q, Sun F, Tie Y, Zhu J, Xing R, Sun Z, Zheng X. 2009. Stress induces tRNA cleavage by angiogenin in mammalian cells. FEBS Lett 583: 437-442.

Gapp K, Miska EA. 2016. tRNA fragments: novel players in intergenerational inheritance. Cell Res 26: 395-396.

Goodarzi H, Liu X, Nguyen HC, Zhang S, Fish L, Tavazoie SF. 2015. Endogenous tRNA-derived fragments suppress breast cancer progression via YBX1 displacement. Cell 161: 790-802.

Gunduz U, Katze JR. 1984. Queuine salvage in mammalian cells. Evidence that queuine is generated from queuosine $5^{\prime}$-phosphate. J Biol Chem 259:1110-1113.

Honda S, Loher P, Shigematsu M, Palazzo JP, Suzuki R, Imoto I, Rigoutsos I, Kirino Y. 2015. Sex hormone-dependent tRNA halves enhance cell proliferation in breast and prostate cancers. Proc Natl Acad Sci 112: E3816-3825.

Honda S, Kawamura T, Loher P, Morichika K, Rigoutsos I, Kirino Y. 2017. The biogenesis pathway of tRNA-derived piRNAs in Bombyx germ cells. Nucleic Acids Res 45: 9108-9120.

Igloi GL, Kossel H. 1985. Affinity electrophoresis for monitoring terminal phosphorylation and the presence of queuosine in RNA. Application of polyacrylamide containing a covalently bound boronic acid. Nucleic Acids Res 13: 6881-6898.

Ivanov P, Emara MM, Villen J, Gygi SP, Anderson P. 2011. Angiogenin-induced tRNA fragments inhibit translation initiation. Mol Cell 43: 613-623.

Ivanov P, O'Day E, Emara MM, Wagner G, Lieberman J, Anderson P. 2014. G-quadruplex structures contribute to the neuroprotective effects of angiogenin-induced tRNA fragments. Proc Natl Acad Sci 111: 18201-18206.

Kasai H, Nakanishi K, Macfarlane RD, Torgerson DF, Ohashi Z, McCloskey JA, Gross HJ, Nishimura S. 1976. Letter: the structure of $\mathrm{Q}^{*}$ nucleoside isolated from rabbit liver transfer ribonucleic acid. J Am Chem Soc 98: 5044-5046.
Kirchner S, Ignatova Z. 2015. Emerging roles of tRNA in adaptive translation, signalling dynamics and disease. Nat Rev Genet 16: 98-112.

Kumar P, Kuscu C, Dutta A. 2016. Biogenesis and function of transfer RNA-related fragments (tRFs). Trends Biochem Sci 41: 679-689.

Lee YS, Shibata Y, Malhotra A, Dutta A. 2009. A novel class of small RNAs: tRNA-derived RNA fragments (tRFs). Genes Dev 23: 2639-2649.

Li H, Handsaker B, Wysoker A, Fennell T, Ruan J, Homer N, Marth G, Abecasis G, Durbin R; Genome Project Data Processing Sungroup. 2009. The Sequence Alignment/Map format and SAMtools. Bioinformatics 25: 2078-2079.

Meier F, Suter B, Grosjean H, Keith G, Kubli E. 1985. Queuosine modification of the wobble base in tRNA ${ }^{\text {His }}$ influences 'in vivo' decoding properties. EMBO J 4: 823-827.

Muller M, Hartmann M, Schuster I, Bender S, Thuring KL, Helm M, Katze JR, Nellen W, Lyko F, Ehrenhofer-Murray AE. 2015. Dynamic modulation of Dnmt2-dependent tRNA methylation by the micronutrient queuine. Nucleic Acids Res 43: 1095210962.

Pathak C, Jaiswal YK, Vinayak M. 2005. Hypomodification of transfer RNA in cancer with respect to queuosine. RNA Biol 2: 143-148.

Phizicky EM, Hopper AK. 2010. tRNA biology charges to the front. Genes Dev 24: 1832-1860.

Raina M, Ibba M. 2014. tRNAs as regulators of biological processes. Front Genet 5: 171.

Rakovich T, Boland C, Bernstein I, Chikwana VM, Iwata-Reuyl D, Kelly VP. 2011. Queuosine deficiency in eukaryotes compromises tyrosine production through increased tetrahydrobiopterin oxidation. J Biol Chem 286: 19354-19363.

Schaefer M, Pollex T, Hanna K, Tuorto F, Meusburger M, Helm M, Lyko F. 2010. RNA methylation by Dnmt2 protects transfer RNAs against stress-induced cleavage. Genes Dev 24: 1590-1595.

Torres AG, Batlle E, Ribas de Pouplana, L. 2014. Role of tRNA modifications in human diseases. Trends Mol Med 20: 306-314.

Vinayak M, Pathak C. 2009. Queuosine modification of tRNA: its divergent role in cellular machinery. Biosci Rep 30: 135-148.

Yamasaki S, Ivanov P, Hu GF, Anderson P. 2009. Angiogenin cleaves tRNA and promotes stress-induced translational repression. J Cell Biol 185: 35-42.

Yasukawa T, Suzuki T, Ishii N, Ohta S, Watanabe K. 2001. Wobble modification defect in tRNA disturbs codon-anticodon interaction in a mitochondrial disease. EMBO J 20: 4794-4802.

Zaborske JM, DuMont VL, Wallace EW, Pan T, Aquadro CF, Drummond DA. 2014. A nutrient-driven tRNA modification alters translational fidelity and genome-wide protein coding across an animal genus. PLoS Biol 12: e1002015.

Zallot R, Brochier-Armanet C, Gaston KW, Forouhar F, Limbach PA, Hunt JF, de Crecy-Lagard V. 2014. Plant, animal, and fungal micronutrient queuosine is salvaged by members of the DUF2419 protein family. ACS Chem Biol 9: 1812-1825.

Zheng G, Qin Y, Clark WC, Dai Q, Yi C, He C, Lambowitz AM, Pan T. 2015. Efficient and quantitative high-throughput tRNA sequencing. Nat Methods 12: 835-837. 

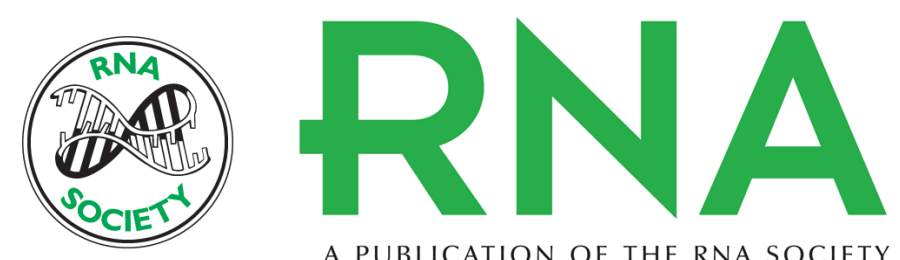

A PUBLICATION OF THE RNA SOCIETY

\section{Queuosine modification protects cognate tRNAs against ribonuclease cleavage}

Xiaoyun Wang, Zaneta Matuszek, Yong Huang, et al.

RNA 2018 24: 1305-1313 originally published online July 3, 2018

Access the most recent version at doi:10.1261/rna.067033.118

\section{Supplemental http://rnajournal.cshlp.org/content/suppl/2018/07/03/rna.067033.118.DC1 Material}

References This article cites 41 articles, 11 of which can be accessed free at: http://rnajournal.cshlp.org/content/24/10/1305.full.html\#ref-list-1

Creative This article is distributed exclusively by the RNA Society for the first 12 months after the Commons License full-issue publication date (see http://rnajournal.cshlp.org/site/misc/terms.xhtml). After 12 months, it is available under a Creative Commons License (Attribution-NonCommercial 4.0 International), as described at http://creativecommons.org/licenses/by-nc/4.0/. Email Alerting $\begin{aligned} & \text { Receive free email alerts when new articles cite this article - sign up in the box at the } \\ & \text { Service }\end{aligned}$ top right corner of the article or click here.

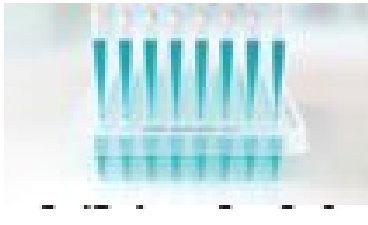

Providing Precise Solutions for your research.

To subscribe to RNA go to:

http://rnajournal.cshlp.org/subscriptions

(C) 2018 Wang et al.; Published by Cold Spring Harbor Laboratory Press for the RNA Society 